\title{
PROTOTIPE ALAT PEMIPIH MELINJO SEMI OTOMATIS
}

\author{
Adung Prawira Adinata ${ }^{1}$, Syufrijal $^{2}$,Massus Subekti ${ }^{3}$ \\ ${ }^{1,2,3}$ Pendidikan Teknik Elektro, Fakultas Teknik, Universitas Negeri Jakarta \\ ${ }^{1}$ E-mail: adungagenkran@gmail.com
}

\begin{abstract}
This research aims to design, create, and test the melinjo squashing machine that could control the electric motor semi-automaticly. The method used is the Research and Development.

The design of a semi-automatic melinjo squashing machine is realized by combining multiple input and output components with a semi-automatic controller as a processing unit. Component inputs used are selectors that serves as a regulator for the machine to run manually or semi-automated and pushbutton function that manually would start the engine. Components such as controlling a semi-automatic process. Output components used function pilot lamp indicates the state of the engine and motor function squashier moving cylinder.

From the research design tool semi automatic melinjo squashier outcome is successfully created and tested. The test results were obtained after the system was tested as a whole, so that it can be concluded that the design of semi-automatic tool of melinjo squashier work fine in accordance with the job description.
\end{abstract}

Keywords : Prototype, melinjo squashing, melinjo, emping, semi automatic.

\begin{abstract}
Abstrak
Penelitian ini bertujuan untuk membuat dan menguji mesin pemipih melinjo yang dapat menghidupkan motor listrik dengan semi otomatis. Metode penelitian yang digunakan adalah Research and Development. Prototipe mesin pemipih melinjo semi otomatis ini diwujudkan dengan menggabungkan beberapa komponen. Komponen input yang digunakan yaitu selektor yang berfungsi sebagai pengatur mesin agar dapat berjalan secara manual maupun semi otomatis dan pushbutton berfungsi menyalakan mesin secara manual. Komponen proses berupa pengendali semi otomatis. Komponen output yang digunakan pilot lamp berfungsi menandakan keadaan mesin, dan motor yang berfungsi menggerakan silinder pemipih.

Dari hasil penelitian prototipe alat pemipih melinjo semi otomatis berhasil dibuat dan diuji. Hasil pengujian diperoleh setelah sistem diuji secara keseluruhan, sehingga dapat disimpulkan bahwa prototipe alat pemipih melinjo semi otomatis bekerja dengan baik sesuai dengan deskripsi kerja.
\end{abstract}

Kata Kunci: Alat, pemipih melinjo, melinjo, emping, dan semi otomatis.

\section{PENDAHULUAN}

Usaha emping di Jakarta banyak terdapat di daerah Condet yang umumnya para penjual masih memproduksi emping melinjo secara manual dalam pembuatannya sehingga lama dalam proses produksi emping. Hal ini tetap dilakukan oleh penjual emping di Condet karena meski lama produksinya kualitas dari emping yang dihasilkan ialah kualitas emping yang bermutu tinggi. Sampai sekarang, pembuatan emping yang bermutu tinggi masih belum dapat dilakukan dengan bantuan alat mekanis pemipih, emping ini masih harus dipipihkan secara manual oleh pengrajin emping yang telah berpengalaman (Anonim, 2008: 2). Pengusaha kecil lebih memilih mempertahankan usaha mereka secara manual dibandingkan dengan memakai alat karena sebelumnya mereka pernah menggunakan alat memang produksi yang dihasilkan lebih cepat daripada menggunakan manual akan tetapi kualitas mutu yang dihasilkan rendah.
Permasalahan lainnya ialah permintaan akan emping melinjo yang sangat tinggi juga tidak diimbangi dengan waktu produksi yang sangat lama karena masih menggunakan cara manual yakni dengan menggunakan tangan sehingga tidak efisien dalam segi waktu.

Berdasarkan permasalahan tersebut penulis ingin memberikan suatu solusi yaitu dengan membuat alat pemipih melinjo yang dapat memproduksi emping melinjo dengan cepat sehingga efisien dalam segi waktu namun tetap menghasilkan emping melinjo dengan kualitas yang cukup baik dan dalam prosesnya dapat dikendalikan secara semi otomatis.

\section{METODE}

Metode penelitian merupakan suatu cara dalam menganalisis data. Menurut Sugiyono, Metode Penelitian pada dasarnya merupakan cara ilmiah untuk mendapatkan data dengan tujuan dan kegunaan tertentu. Metode penelitian yang digunakan adalah metode 
R\&D Research and Development. Dimana tujuan dari sebuah metode ini adalah untuk membuat suatu produk baru atau untuk menghasilkan suatu produk dan juga untuk menyempurnakan produk yang telah ada. Disini masalah yang dibahas oleh penulis adalah mengatasi ketidakmampuan dari para produsen emping melinjo dalam memenuhi permintaan emping melinjo yang cukup tinggi dipasaran dan dari masalah yang sudah ditentukan diharapkan penulis dapat menemukan perlakuan dan pengaruh yang bisa merubah masalah kondisi tersebut. Metode yang digunakan dapat dilihat pada gambar 1 di halaman berikut:

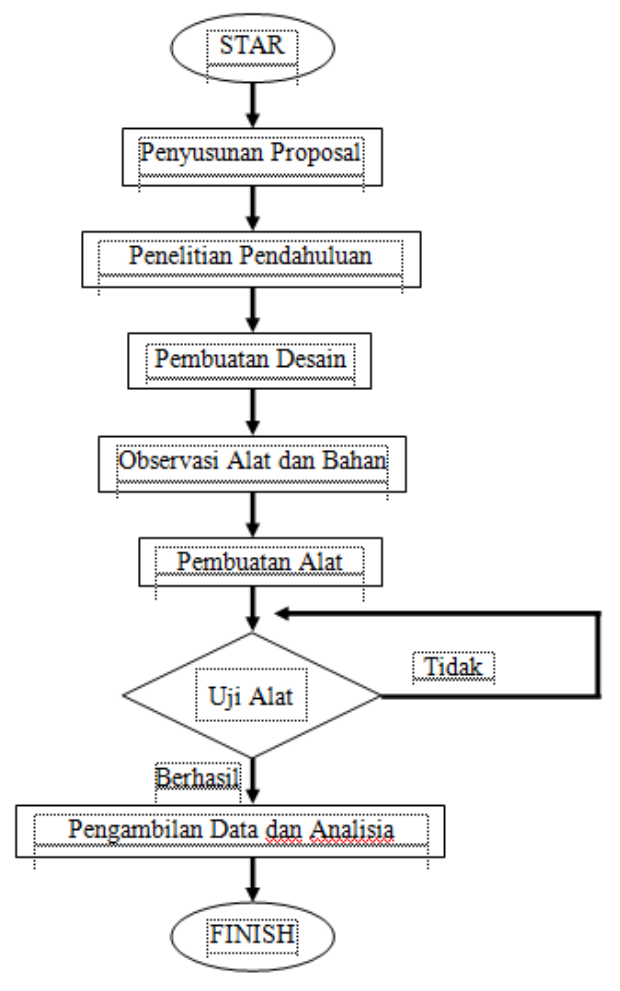

Gambar 1. Flowchart TahapanPenelitian

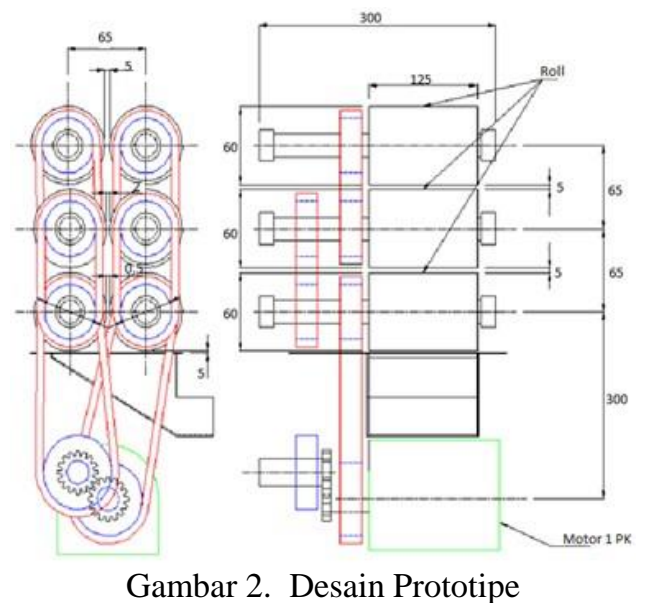

Flowchart sistem alat dapat dilihat pada gambar 3.

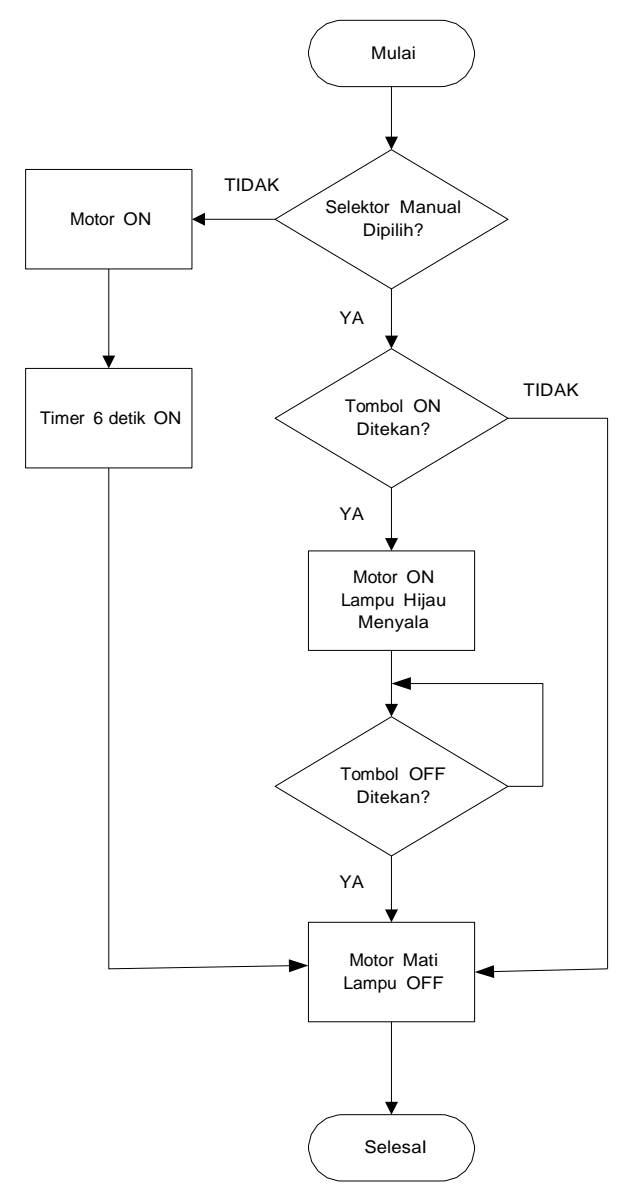

Gambar 3. Flowchart Sitem Alat

\section{HASIL DAN PEMBAHASAN}

Hasil pengujian ini dilakukan dengan membuat rangkaian pada panel kontrol yang menggunakan timer sebagai pengatur waktu yang dapat di setting sesuai keinginan pemakai. 
Dalam penelitian ini waktu yang ditentukan ialah enam detik.

Pemakai dapat mengatur mesin sesuai dengan keinginan pemakainya karena terdapat pula selektor pada panel yang berfungsi sebagai pengatur mesin pemipih melinjo ingin dijalankan dalam keadaan manual atau otomatis dengan menggunakan timer yang telah di setting enam detik.

Jika memilih menu manual pada selector, maka jika Push Button On ditekan maka lampu indikator hijau menyala dan motor pun ikut menyala. Setelah motor berputar maka akan menggerakan pulley penggerak. Pulley penggerak berputar menggerakan pully yang lainnya. Pulley yang digerakkan memutar poros, kemudian poros berputar menggerakan silinder pemipih sehingga silinder pemipih bergerak memipihkan biji melinjo. Jika Push Button OFF ditekan maka motor berhenti bergerak, lampu indikator tidak ada yang menyala dan proses pemipihan selesai.

Pengujian tegangan pada mesin bertujuan untuk mengetahui besarnya tegangan yang masuk pada mesin pemipih melinjo ini baik saat kondisi mesin mati maupun dalam kondisi mesin menyala. Berdasarkan hasil pengujian tegangan pada mesin pemipih melinjo yang disajikan pada tabel 1, pada kondisi mesin dalam keadaan mati tegangan yang terukur adalah sebesar 0 Volt. Sementara pada kondisi mesin menyala, tegangan yang terukur ialah 216 Volt.

Pada rangkaian pengendali motor mendapat sumber AC 220,6 V. Pada saat motor tanpa beban maka tegangan pada motor 0 volt, sedangkan motor dalam keadaan berbeban atau proses pemipihan maka tegangan yang ada pada motor $216 \mathrm{~V}$ AC tidak berbeda jauh dengan tegangan sumber. Putaran motor terukur dengan putaran $180 \mathrm{rpm}$. Sedangkan putaran silinder pemipih pada bagian atas ialah $60,9 \mathrm{rpm}$, bagian tengah silinder pemipih ialah 62,9 rpm serta pada bagian bawah silinder pemipih ialah $65 \mathrm{rpm}$.
Jika memilih menu auto pada selektor maka lampu indikator hijau akan langsung menyala dan motor pun ikut menyala. Setelah motor berputar maka akan menggerakan pulley penggerak. Pulley penggerak berputar menggerakan pully yang lainnya. Pulley yang digerakkan memutar poros, kemudian poros berputar menggerakan silinder pemipih sehingga silinder pemipih bergerak memipihkan biji melinjo. Setelah enam detik maka motor akan berhenti bergerak secara otomatis, lampu indikator tidak ada yang menyala dan proses pemipihan selesai.

Berikut adalah tabel hasil pengujian dan pengukuran tegangan listrik untuk prototipe Alat Pemipih Melinjo Semi Otomatis.

\section{Tabel 1 Hasil Pengujian Tegangan dan Putaran Rangkaian PengendaliMotor}

\begin{tabular}{llllll}
\hline \multirow{2}{*}{ Komponen } & \multirow{2}{*}{ Tegangan } & & $\begin{array}{l}\text { Putaran Roll Putaran Roll Putaran Roll } \\
\text { Bawah }\end{array}$ & $\begin{array}{l}\text { Tengah } \\
\text { Tenas }\end{array}$ \\
\cline { 2 - 6 } & ON & OFF & ON & ON & 0N \\
\hline Motor & 206 Volt & 0 Volt & $65 \mathrm{pm}$ & $62,9 \mathrm{~mm}$ & $60,9 \mathrm{pm}$ \\
\hline
\end{tabular}

Tabel.2

\begin{tabular}{|c|c|c|c|c|c|c|}
\hline No. & P1 & P2 & P3 & P4 & P5 & Keterangan \\
\hline 1 & $\sqrt{ }$ & $\sqrt{ }$ & v & $\sqrt{ }$ & $\sqrt{ }$ & \\
\hline 2 & $\checkmark$ & $\checkmark$ & $\sqrt{ }$ & $\checkmark$ & $\checkmark$ & \\
\hline 3 & $\checkmark$ & $\checkmark$ & $\sqrt{ }$ & $\mathrm{x}$ & $\sqrt{ }$ & \\
\hline 4 & $\mathrm{x}$ & $\mathrm{x}$ & $\mathrm{x}$ & $\sqrt{ }$ & $\checkmark$ & \\
\hline 5 & $\mathrm{x}$ & $\sqrt{ }$ & $\mathrm{x}$ & $\mathrm{x}$ & $\checkmark$ & \\
\hline 6 & $\checkmark$ & $\sqrt{ }$ & $\checkmark$ & $\sqrt{ }$ & $\mathrm{x}$ & \\
\hline 7 & $\sqrt{ }$ & $\mathrm{x}$ & $\sqrt{ }$ & 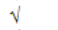 & $\sqrt{ }$ & \\
\hline 8 & $\mathrm{x}$ & $\sqrt{ }$ & $\checkmark$ & $\sqrt{ }$ & 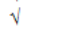 & \\
\hline 9 & $\sqrt{ }$ & v & $\mathrm{x}$ & $\mathrm{x}$ & $\mathrm{x}$ & \\
\hline 10 & V & v & v & v & v & \\
\hline \multicolumn{7}{|c|}{ Keterangan: } \\
\hline $\mathrm{P} 1$ & \multirow{5}{*}{\multicolumn{6}{|c|}{$\begin{array}{l}\text { Percobaan pertama proses pemipihan melinjo yang telah disangrai } \\
\text { Percobaan kedua proses pemipihan melinjo yang telah disangrai } \\
\text { Percobaan ketiga proses pemipihan melinjo yang telah disangrai } \\
\text { Percobaan keempat proses pemipihan melinjo yang telah disangrai } \\
\text { Percobaan kelima proses pemipihan melinjo yang telah disangrai }\end{array}$}} \\
\hline P2 & & & & & & \\
\hline P3 & & & & & & \\
\hline P4 & & & & & & \\
\hline P5 & & & & & & \\
\hline No & \multicolumn{6}{|c|}{ Menandakan urutan percobaan yang dilakukan } \\
\hline
\end{tabular}

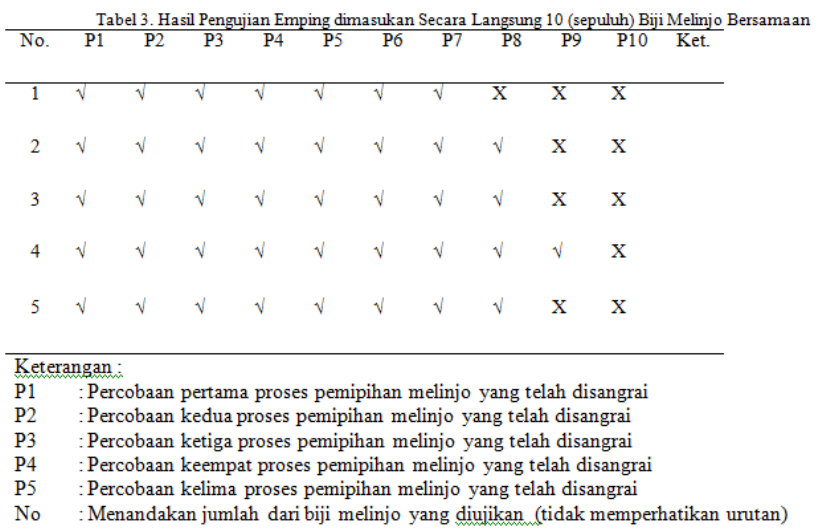


Mesin diuji untuk memipihkan melinjo dalam dua tahapan yakni tahapan pertama melinjo dimasukkan satu per satu kedalam mesin pemipih melinjo dan tahapan kedua biji melinjo dimasukkan langsung sepuluh sepuluh ke dalam mesin pemipih. Dalam tahap pertama, pengujian melinjo yang diuji berjumlah 50 buah dimana hasil pengujian ini biji melinjo dimasukkan satu per satu ke dalam mesin kemudian data hasil pengujian dimasukkan ke dalam tabel yang terbagi menjadi lima bagian. Hal ini dimaksudkan untuk mengetahui tingkat keberhasilan dari proses pemipihan biji melinjo tersebut.

Dalam tahap kedua, pengujian melinjo yang diuji berjumlah 50 buah dimana hasil pengujian ini biji melinjo dimasukkan sepuluh sepuluh biji

\begin{tabular}{cc} 
Trabel 4.Hasil Pengujian Arus Mesin Pemipih Melinjo \\
\hline No & $\begin{array}{c}\text { Arus } \\
\text { (mA) }\end{array}$ \\
\hline 1 & 381,8 \\
2 & 381,6 \\
3 & 380,2 \\
4 & 385,5 \\
5 & 385,2 \\
6 & 376 \\
7 & 367 \\
8 & 370,5 \\
9 & 383,9 \\
10 & 373,3
\end{tabular}

Total rata-rata $\quad 378,5$

Pengujian dilakukan untuk mengetahui berapakah besarnya arus pada motor. Pengujian dilakukan pada saat kondisi motor bergerak (aktif). Pengujian dilakukan dengan cara mengukur arus yang ada pada rangkaian. Hasil pengujian rangkaian pengendali motor akan melinjo secara bersamaan ke dalam mesin kemudian data hasil pengujian dimasukkan ke dalam tabel yang terbagi menjadi lima bagian. Hal ini dimaksudkan untuk mengetahui tingkat keberhasilan dari proses pemipihan biji melinjo tersebut.

Berdasarkan kedua data tersebut maka maka dapat disimpulkan bahwa mesin pemipih melinjo bekerja sesuai rencana dan berhasil memipihkan melinjo dengan cukup baik, hal ini terbukti dengan pengujian dari 100 biji melinjo yang diujikan terdapat 77 ( $77 \%$ ) biji melinjo yang dapat dipipihkan dengan baik dan 23 ( $23 \%$ ) biji melinjo yang belum sempurna karena merekat pada roll silinder mesin tetapi dari segi tingkat pemipihan tetap cukup baik.

memperlihatkan besar arus pada saat motor tersebut bergerak (aktif). Pengujian dilakukan sebanyak 10 (sepuluh) kali pengujian secara terus - menerus tanpa henti dengan mempertimbangkan waktu. Pengujian pada rangkaian diukur setiap menit selama 10 (sepuluh) menit

Berdasarkan perhitungan, data arus pada penelitian ini memperoleh nilai rata - rata 378,5 $\mathrm{mA}$ dengan tegangan yang diperoleh 216 Volt, maka dengan demikian kita dapat mengetahui berapa besarnya daya yang diperlukan rumus daya $P=V \times I$ sehingga diperoleh $P=216 x$ 378,5 Sehingga $P=81,8$ Watt. Jadi untuk pengoperasian alat pemipih melinjo semi otomatis diperlukan daya sebesar 81,8 Watt.

\section{Kelebihan Alat}

Kelebihan alat ini hasil pemipihan maksimal, dapat mengendalikan motor secara semi otomatis, operator dapat mengendalikan secara manual ataupun otomatis karena dilengkapi dengan selektor auto manual serta timer. Hasil pemipihan yang dihasilkan pun cukup merata. Mudah untuk dibawa karena memiliki bentuk yang tidak terlalu besar, terdapat roda untuk mempermudah proses pemindahan, memiliki berat cukup ringan yaitu $42 \mathrm{~kg}$ dan konsumsi daya untuk penggunaan mesin pemipih melinjo ini hanya 81,8 Watt. 


\section{Kekurangan Alat}

Dari beberapa kali pengujian masih ditemukan hasil pipihan melinjo yang menempel pada roll dan masih ditemukan pula melinjo yang tidak rata proses pemipihannya. Selain itu proses pembuatannya masih memerlukan biaya yang cukup tinggi.

\section{KESIMPULAN DAN SARAN \\ Kesimpulan}

Berdasarkan hasil penelitian yang telah dilaksanakan, alat pemipih melinjo semi otomatis ini dapat bekerja sesuai dengan fungsinya, yaitu memipihkan melinjo dengan motor listrik secara semi otomatis berdasarkan rangkaian pengontrolan. Kesimpulan yang dapat diambil dari kegiatan penelitian rancang bangun alat pemipih melinjo semi otomatis adalah sebagai berikut:

1. Sistem mampu memipihkan melinjo secara semi otomatis.

2. Sistem mampu bekerja dengan baik, baik untuk rangkaian manualnya ataupun rangkaian pengontrol otomatisnya.

3. Dari beberapa kali percobaan masih ada melinjo yang belum terpipih sempurna hal ini dikarenakan ketidaksempurnaan dalam pembubutan poros silinder pemipih sehingga terdapat beberapa perputaran silinder pemipih masih belum sempurna.

4. Dari beberapa kali percobaan masih ada melinjo yang menempel di roll mesin pemipih melinjo hal ini disebabkan oleh getah dari biji melinjo, biji melinjo yang dimasukkan terlalu muda, dan biji melinjo yang dimasukkan belum matang

5. Daya total yang digunakan dalam rangkaian alat sebesar 81,8 Watt.

\section{Saran}

Dari hasil penelitian dan uji coba, penulis dapat memberikan beberapa saran yang dapat dipertimbangkan, yaitu:

1. Pilihlah biji melinjo yang benar-benar matang, yakni buah melinjo yang berwarna orange tua atau merah dan kulit dalamnya berwarna coklat kehitaman dan mengkilat agar biji melinjo tidak menempel pada silinder pemipih.

2. Gilinglah biji melinjo ketika masih hangat dengan segera agar memperoleh hasil pipihan yang diharapkan, jika melinjo sudah kembali dingin hasil melinjo tidak akan sesuai harapan karena biji melinjo menjadi keras kembali sehingga sulit untuk dipipihkan.

3. Pasanglah pisau dengan bantuan per besi pada silinder pemipih sehingga ketika ada biji melinjo yang menempel pada silinder pemipih dapat terlepas dengan sendirinya dengan bantuan pisau.

4. Perhatikan K3 (Kesehatan Keselamatan Kerja) selama kegiatan pemipihan melinjo berlangsung agar terhindar dari kecelakaan kerja yang tidak diinginkan.

5. Lakukan pelumasan pada bagian-bagian yang berputar.

6. Bersihkan mesin sebelum dan setelah digunakan.

7. Tutup Hopper setelah selesai digunakan agar tidak ada debu yang masuk ke dalam mesin pemipih melinjo.

8. Perlu adanya rangkaian pembalik yang berfungsi untuk membersihkan bagian dalam mesin.

\section{DAFTAR PUSTAKA}

(Anonim). (1986). Cara Bertanam Melinjo dan Pembuatan Emping. Dinas Perkebunan D.I. Yogyakarta

(Anonim). (2008). PPUP Emping Melinjo. Jakarta. Bank Indonesia

Berry,S.K. (1980). "Cyclopropene fatty acids in Cnetum gnemon L., seed and leaves", Journal of The Science of Food and Agriculture, Malaysia University of Agriculture Serdang, Malaysia

Cadiz RT, Florido HB. (2001). Bago: Gnetum gnemon Linn. Research Information System. Jakarta

Devi, Nirmala. (2010). Nutrition and Food Gizi untuk Keluarga. Jakarta: Penerbit Buku Kompas 
Hariana, Arief. (2008). Tumbuhan Obat dan Khasiatnya Seri 2. Jakarta: Swadaya

Jakson, K.G. (1994). Kamus Teknik Listrik. Jakarta: PT. Gramedia

Joseph E. S dan Larry D. M, (1984). Perencanaan Teknik Mesin. Ed Ke-4 Jilid 2. Jakarta: Erlangga

Kurniawan Kholik, Motor kapasitor star dan motor kapasitor running, http://kuniawankholik.blogspot.com/2013/10/ v-behaviourdefaultvmlo.html. Diakses 13 April 2015

Maulana, Indra. 2011. Pembuatan Mesin Emping Melinjo Dengan Sistem Silinder
Bertenaga Listrik Untuk UKM. [Skripsi]. Surabaya: Fakultas Teknik, Sekolah Tinggi Teknik Surabaya

Muhammad Hasanudin Abdul Qadir, Pilot Lamp, http://masterwebsite.blogspot.in/2012/04/pilot -lamp.html. Diakses 13 April 2015

Putjiatmoko. (2007). Potensi Melinjo di Jepang. Jakarta

Sunanto, Hatta. (1991). Budidaya Melinjo dan Usaha Produksi Emping.Yogyakarta:

Kanisius

Wahyuni, Dila Resti. 2015. Alat Pemipil Jagung Otomatis Berbasis Programmable Logic Control (PLC). [Skripsi]. Jakarta: Fakultas Teknik, Universitas Negeri Jakarta 